\title{
INFRAESTRUTURA VERDE: CONCEITOS, TIPOLOGIAS E TERMINOLOGIA NO BRASIL
}

\section{GREEN INFRASTRUCTURE: CONCEPTS, TYPOLOGIES, AND TERMINOLOGY IN BRAZIL}

\author{
Maria Fernanda Nóbrega dos Santos \\ Marta Enokibara
}

\begin{abstract}
RESUMO
A Infraestrutura Verde (IV) tem se destacado na última década enquanto frente de pesquisa interdisciplinar, capaz de agregar questões ambientais, econômicas e sociais no desenvolvimento de projetos urbanos mais sustentáveis. Para alcançar tais objetivos, é necessária a inclusão de profissionais de formações diversas nos projetos, que muitas vezes possuem acepções distintas do seu significado e abrangência. Desse modo, o presente trabalho se propõe a apresentar um panorama atual das publicações sobre IV no Brasil, com o objetivo de identificar os conceitos, tipologias e terminologia. Foram levantados 1146 documentos publicados em português (entre 1999-2018) que continham o termo IV, sendo 235 artigos em periódicos nacionais indexados. Desse material, 75 artigos apresentaram uma definição de IV, que são o corpus de pesquisa e compuseram uma ampla base de dados sobre o tema da IV no Brasil, disponibilizada como material suplementar deste artigo. Além de autores da área de Arquitetura, Urbanismo e Paisagismo, foram identificadas outras áreas: Geografia, Direito, Ciências Biológicas, Engenharia Civil, Engenharia Ambiental, Gestão e Análise Ambiental, Engenharia Florestal e Publicidade e Propaganda. Ao todo, foram citadas 40 referências bibliográficas para definir a IV e observa-se uma tendência dos estudos atuais em enfocar tipologias para manejo de águas pluviais. Destaca-se, ainda, a divergência na terminologia usada: dos 125 termos catalogados para designar as tipologias de IV, apenas 65 são citados por mais de um autor, corroborando a necessidade e importância de estudos transversais sobre o tema.
\end{abstract}

Palavras-chave: Arquitetura paisagística. Infraestrutura Verde. Revisão da literatura.

\section{ABSTRACT}

Green infrastructure (GI) has emerged in the last decade as an interdisciplinary research field, capable of addressing environmental, economic and social issues in the development of more sustainable urban design. To achieve these objectives, professionals from several areas must engage in planning, and they often diverge on the meaning and scope of GI. Therefore, this work aims to present a review on GI publications in Brazil, focusing on identifying the different research fields, their concepts, typologies, and terminology. The survey identified 1146 documents that were published in Portuguese (from 1999 to 2018), which contained the term $\mathrm{Gl}$, and 235 were national peer-reviewed papers. Within this material, 75 texts presented a definition of $\mathrm{Gl}$, which composed a dataset regarding GI in Brazil, available as supplementary material. Besides Architecture, Urbanism, and Landscaping, authors from other areas were identified: Geography, Law, Biological Sciences, Civil Engineering, Forest Engineering, Environmental Engineering, Environmental Management and Analysis, and Advertising and Marketing. Regarding the GI concept, 40 bibliographic references were used, and a current trend on studies focusing on urban stormwater management typologies was noticed. It is also noteworthy the divergence surrounding GI terminology: 125 terms were catalogued to designate Gl typologies, but only 65 were mentioned by more than one author, corroborating the need and importance of cross-sectional studies on the topic.

Keywords: Landscape architecture. Green infrastructure. Literature review. 


\section{INTRODUÇÃO}

A busca por estratégias para atenuação dos impactos da urbanização no ciclo hidrológico contribuiu para o surgimento de diversas abordagens para o manejo das águas pluviais baseadas nos conceitos de detenção e infiltração (SCHUELER, 1987; URBONAS; STARE, 1993). Como qualquer área em expansão, a terminologia ao redor do assunto reflete esse rápido incremento e diversificação. Conforme bem discutido por Fletcher et al. (2015), apesar da grande variedade de termos - Sustainable Urban Drainage System (SUDS) no Reino Unido, Water Sensitive Urban Design (WSUD) na Austrália, Best Management Practices (BMP), Low Impact Development (LID) e Green Infrastructure (GI) nos EUA, Compensatory Techniques (CT) na França e Brasil, dentre outros - as diversas abordagens integradas possuem grande confluência de objetivos.

Nos campos da Arquitetura, Urbanismo e Paisagismo, o termo GI e sua tradução em português, Infraestrutura Verde (IV), tem sido mais utilizado, em virtude de suas raízes na Arquitetura Paisagística e na Ecologia de Paisagens. Ainda segundo Fletcher et al. (2015), o termo surgiu nos EUA na década de 1990 e foi difundido por Benedict e McMahon (2006). Não obstante, é relevante frisar que a IV não se refere apenas às estratégias integradas para manejo de águas pluviais, sendo um conceito mais abrangente. A primeira definição de IV em um periódico nacional é apresentada por Cormier e Pellegrino (2008, p. 128) a partir da tradução de Benedict e McMahon (2006):

Essa rede de espaços interconectados, na escala do planejamento urbano e regional, pode ser vista como uma "infraestrutura verde", composta de áreas naturais e outros tipos de espaços abertos que conservam os valores dos ecossistemas naturais e suas funções como mananciais, controle ambiental, regulação climática, recreação e lazer, provendo uma ampla gama de benefícios para a sociedade.

Denota-se, a partir do conceito de IV apresentado, o caráter integrado e multifuncional desses espaços naturais que, por estarem inseridos no urbano, precisam atender a distintas demandas - relacionadas tanto aos usos da população, quanto ao provimento de Serviços Ecossistêmicos. Nesse ponto, muitos autores posteriores se dedicaram a detalhar essas funções, como os trabalhos pioneiros desenvolvidos por Franco (2010), Herzog e Rosa (2010) e Ferreira e Machado (2010).

Duas décadas após as primeiras menções à IV em publicações acadêmicas brasileiras (RIBEIRO, 2000; KLECHOWICZ, 2001; GIORDANO, 2004), e 11 anos após a conceituação seminal apresentada por Cormier e Pellegrino (2008), a IV tem se consolidado cada vez mais como uma importante frente de trabalho e pesquisa dentro da Arquitetura, Urbanismo e Paisagismo. Ao mesmo tempo, a colaboração de profissionais de outras áreas do conhecimento é cada vez valorizada no desenvolvimento desses projetos e contribui para aumentar a complexidade do trabalho e a necessidade de integração. Afinal, se a adoção de uma determinada terminologia depende dos profissionais envolvidos, trabalhar com equipes interdisciplinares sem antes compreender essas diferenças pode se tornar uma barreira aos projetos - o que torna o momento propício para se conduzir uma avaliação transversal do conteúdo produzido sobre o tema.

Para tanto, a revisão da literatura associada a análises bibliométricas configura-se como importante instrumento para síntese, avaliação e identificação de tendências na geração do conhecimento científico. Pressupondo a IV enquanto campo de pesquisa em expansão, é de suma relevância a condução de estudos dessa natureza, visando assentar as bases do conhecimento até agora obtidos e orientar futuras investigações. Assim, o objetivo deste trabalho é apresentar um panorama atual das publicações sobre IV no Brasil, com enfoque na identificação das diferentes áreas que estão pesquisando o tema e como isso se reflete nos seus conceitos, tipologias ${ }^{1}$ e termi-

1 Tipologia: o termo será utilizado neste trabalho para designar os diferentes elementos considerados pelos autores como sendo parte da IV. O trabalho de Cormier e Pellegrino (2008) foi o primeiro artigo nacional a se referir às 'tipologias de IV' e contribuiu na disseminação do termo, que hoje adquire um significado mais amplo que a definição inicial dada pelos autores. Discussões à parte, a adoção do termo 'tipologia de IV' se justifica pelo fato de a locução ser genericamente utilizada pelos autores da área para se referirem tanto às diferentes estratégias para o manejo integrado das águas pluviais (jardins de chuva, 


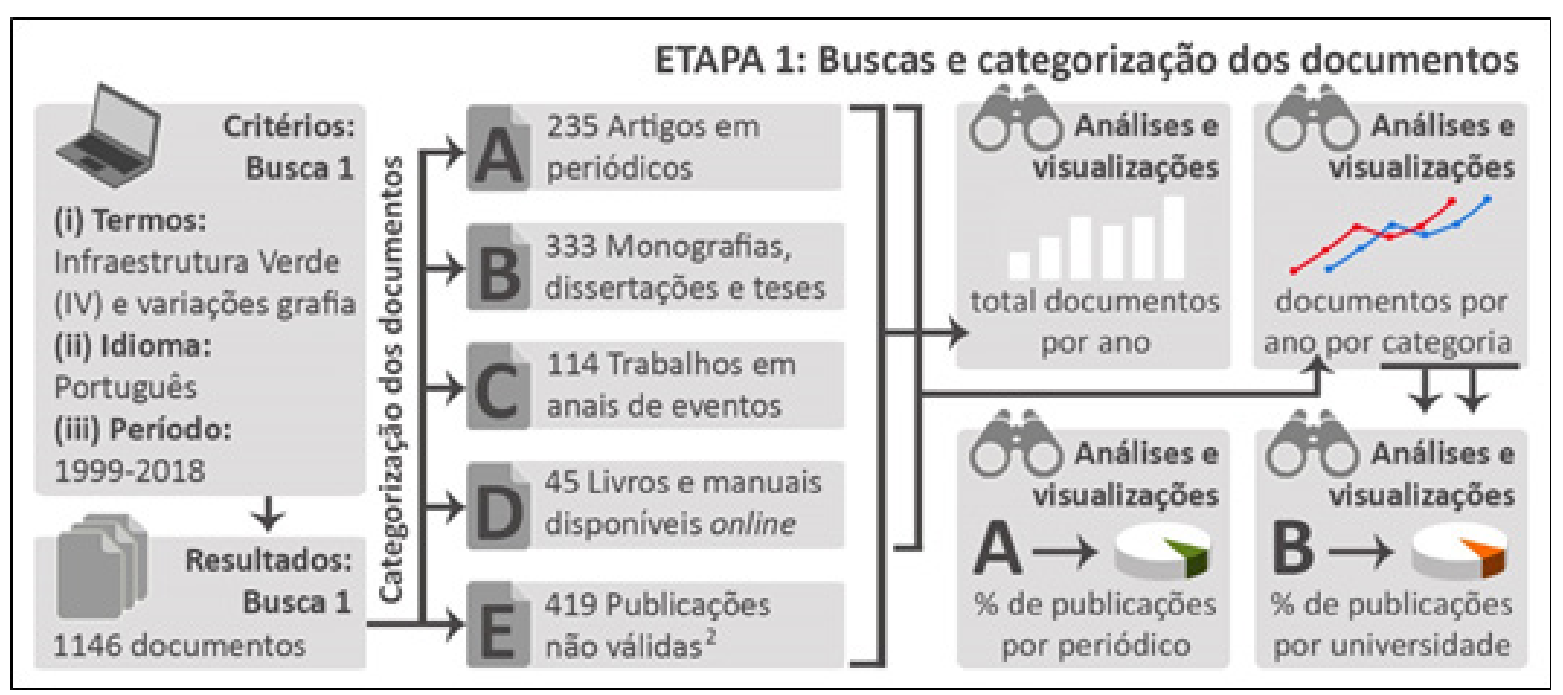

Figura 1: Fluxograma da primeira etapa de pesquisa: critérios de busca no Google Acadêmico e categorização dos documentos com o termo IV publicados em português entre 1999-2018. Fonte: Produzido por Santos (2020)

nologia usada, por meio da revisão da literatura associada a análises bibliométricas.

\section{Material e Métodos}

A revisão da literatura sobre o tema da IV no Brasil teve como base o Google Acadêmico pela sua abrangência: além de periódicos, livros e trabalhos publicados em anais de eventos, também estão disponíveis monografias, dissertações e teses. Ademais, o Google Acadêmico possui maior cobertura para idiomas nãoanglófonos (MEHO; YANG, 2007) e grande sobreposição a bases tradicionais como Scopus, Web of Science e Microsoft Academic Search (ORDUNA-MALEA et al., 2015). Foi avaliada a ocorrência dos termos combinados 'infraestrutura verde' e suas possíveis variações de grafia 'infraestruturas verdes', 'infra-estrutura verde' e 'infra-estruturas verdes', em qualquer lugar do corpo do texto nos documentos disponíveis em língua portuguesa. $\mathrm{O}$ levantamento foi realizado no mês de julho de 2019 e haja vista o amplo alcance da busca, a cobertura temporal foi delimitada em 20 anos, compreendendo os documentos publicados entre

biovaletas, canteiros pluviais etc.), quanto alguns elementos construtivos (tetos verdes, pavimentos permeáveis etc.), diferentes práticas (como arborização urbana, agricultura urbana etc.) ou ainda diversos tipos de espaços (na acepção atual, sejam eles urbanos ou não, tratados paisagisticamente ou não)
1999-2018. Acredita-se que, assim, se garanta atualidade à análise do tema, ao mesmo tempo que se assegure um grande volume de dados. Conforme representado na Figura 1, a busca retornou 1146 documentos, que foram preliminarmente analisados e classificados em 5 categorias: (A) artigos em periódicos; (B) monografias, dissertações e teses; (C) trabalhos em anais de eventos; (D) livros e manuais e (E) publicações não válidas².

Algumas análises preliminares foram realizadas a fim de identificar as principais tendências nas publicações sobre IV no Brasil. Nessa avaliação, foram utilizados os resultados brutos do levantamento (categorias A, B, C, D e E) publicados por ano, para o período analisado (20 anos). Os documentos também foram avaliados por categoria: número de publicações válidas totais por categoria ao ano (categorias $A, B, C, D$ ); número de publicações de

2 A categoria $\mathrm{E}$ (publicações não válidas) é composta principalmente de documentos que apesar de terem sido publicados em língua portuguesa, são provenientes de Portugal e outras nações lusófonas. Como o foco deste trabalho é avaliar a evolução do tema no Brasil, esses documentos foram agrupados em uma categoria separada. Além disso, também foram abrangidos nessa categoria os documentos duplicados e outros materiais erroneamente retornados como resultados válidos. Essa é uma das limitações na acurácia dos resultados do Google Acadêmico, como ponde filtragem procurou diminuir. Outra limitação na interpretação dos resultados diz respeito ao dinamismo dos conteúdos disponíveis on-line, haja vista que novos documentos são constantemente adicionados, modificados ou excluídos, influenciando no número de resultados retornados pelo Google Acadêmico em um dado momento, como mencionado por Orduna-Malea et al. (2015). 


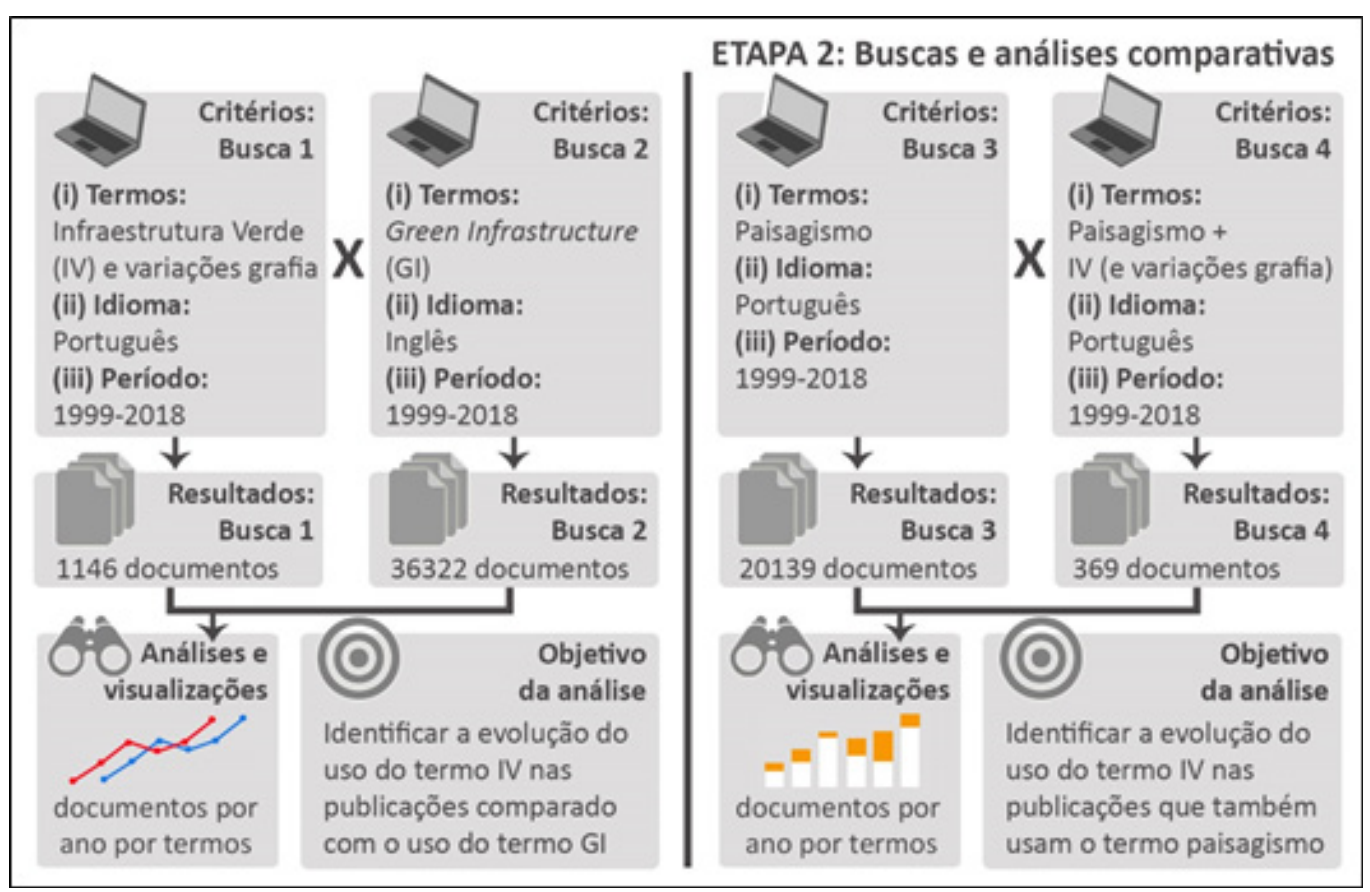

Figura 2: Fluxograma da segunda etapa de pesquisa: critérios de busca no Google Acadêmico e condução de análises comparativas para identificar macrotendências nas publicações em IV.

Fonte: Produzido por Santos (2020).

monografias, dissertações e teses (categoria B) por universidade; e número de publicações de artigos (categoria A) por periódico.

\subsection{ANÁlise de MACROTENDÊNCIAS}

Para discussão desses resultados, é interessante correlacionar a evolução das publicações sobre IV paralelamente ao desenvolvimento da área na qual o tema inicialmente se originou, o Paisagismo. Assim, uma nova rodada de pesquisa no Google Acadêmico foi realizada para o mesmo período e condições, para levantar o total de documentos que possuem o termo 'paisagismo' e, desses, os documentos que contêm simultaneamente o termo 'paisagismo' e 'IV' (e variações).

Ainda para efeitos de discussão, pesquisou-se também no Google Acadêmico a evolução ao longo do tempo do uso do termo 'IV' (e variações) em comparação ao uso do termo 'green infrastructure', seu equivalente em Inglês. Essa avaliação é interessante para compreender se as dinâmicas que ocorrem nas publicações de língua portuguesa estão em consonância com as tendências mundiais - tendo em vista que grande parte das publicações internacionais adota a língua inglesa. O fluxograma dessa etapa da pesquisa está ilustrado na Figura 2.

\subsection{ANÁlise dos ARTIGOS EM PERIÓdicos INDEXAdOS}

Na sequência, procedeu-se à avaliação detalhada que corresponde ao foco principal do trabalho: o levantamento das diversas áreas de conhecimento envolvidas nesse campo de estudo interdisciplinar e como isso se reflete nos conceitos, tipologias e terminologia usada. Para essa análise, foram selecionados somente os artigos em periódicos (categoria A) - considerando que foram submetidos ao processo de revisão por pares - e realizada a leitura exploratória desse material. Foram levantados: título do trabalho, nome do periódico, ano de publicação, nome dos autores e coautores, área de formação do autor principal, palavras-chave utilizadas e, finalmente, se os textos apresentavam uma definição de IV. 


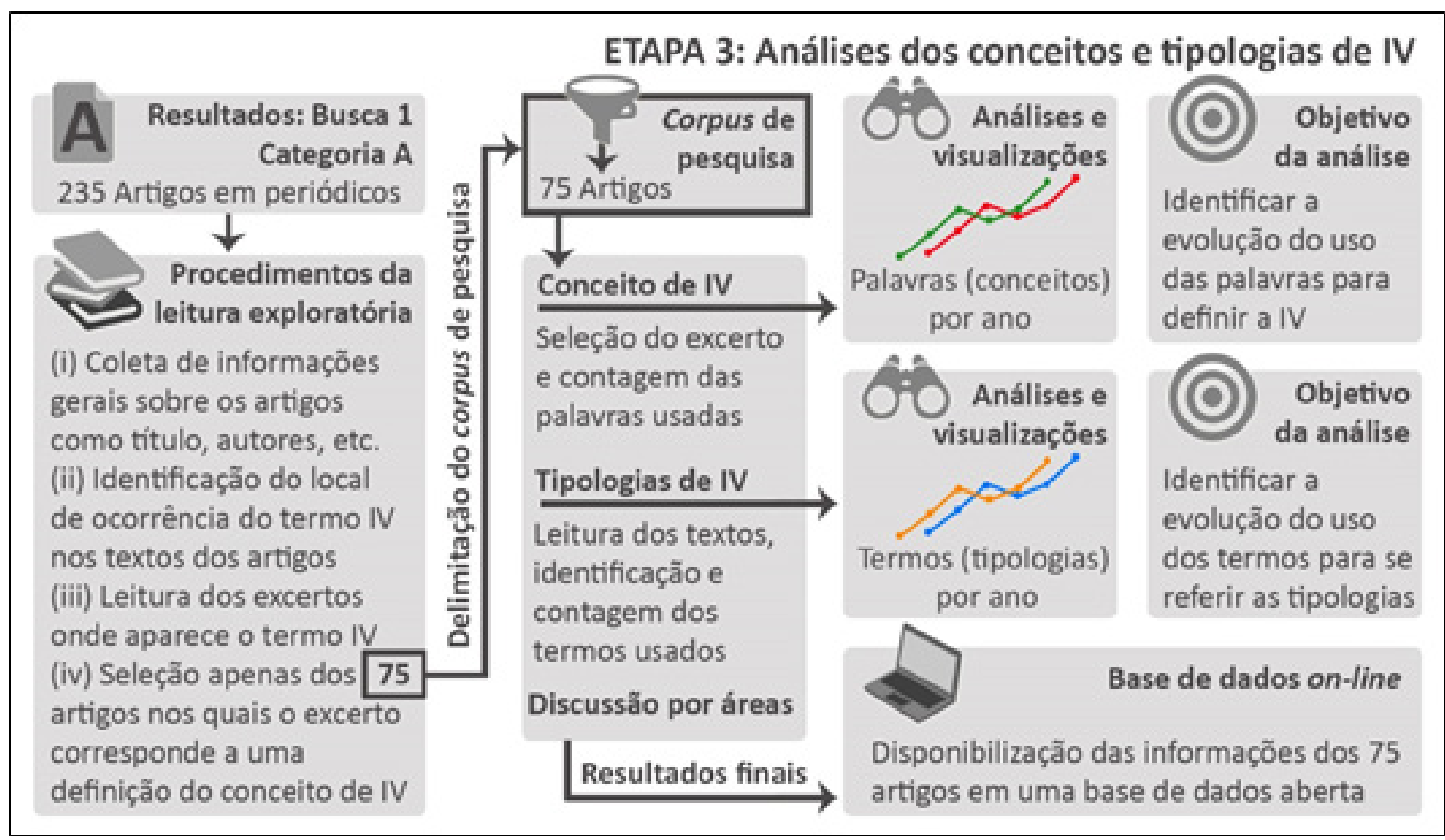

Figura 3: Fluxograma da terceira etapa de pesquisa: procedimentos da leitura exploratória e seleção dos artigos que foram utilizados para mapear os conceitos e tipologias nas publicações em IV. Fonte: Produzido por Santos (2020).

A partir dessas leituras, foram identificados 75 artigos com uma definição de IV, que formaram o corpus de pesquisa. Foi selecionado o excerto do texto em que o conceito era apresentado e realizada uma contagem e análise de frequência das palavras. Além disso, foram contabilizadas nesses textos as referências àquilo que os autores consideravam como tipologias de IV. Sempre que um autor incluía uma nova tipologia, o termo era pesquisado nos 75 arquivos para avaliar a sua ocorrência. Essa etapa da pesquisa encontra-se ilustrada no fluxograma da Figura 3.

Todas essas informações foram compiladas no software Microsoft Excel ${ }^{\circledR}$ e compuseram uma base de dados abrangente sobre o tema da IV no Brasil, que se encontra disponível para download como material suplementar ${ }^{3}$ deste artigo, armazenada no Mendeley Data. Os principais resultados serão expostos e discutidos com o apoio de tabelas e gráficos elaborados a partir do Microsoft Excel®.

3 A base de dados encontra-se armazenada no Mendeley Data, disponível para download em: http://dx.doi.org/10.17632/jnvgdhtmd5.1

\section{Resultados e Discussão}

A apresentação dos resultados foi dividida em três partes principais: análise de macrotendências, abrangendo todos os resultados; detalhamento das categorias, somente resultados válidos; e por fim, uma análise dos conceitos, tipologias e terminologia nos artigos.

\subsection{Macrotendências nas publicações em IV}

A Figura 4 apresenta um gráfico que expõe os documentos que contêm o termo IV, publicados por ano, sendo possível ressaltar dois pontos. Primeiro, apesar de existirem algumas referências anteriores, observa-se que o interesse no tema efetivamente se inicia entre os anos 2006-2007, coincidindo com a publicação do livro de Benedict e McMahon (2006). Segundo, destaca-se o franco crescimento no número de publicações que fazem referência à IV, principalmente na segunda década analisada (2009-2018), após a publicação do artigo de Cormier e Pellegrino (2008). 


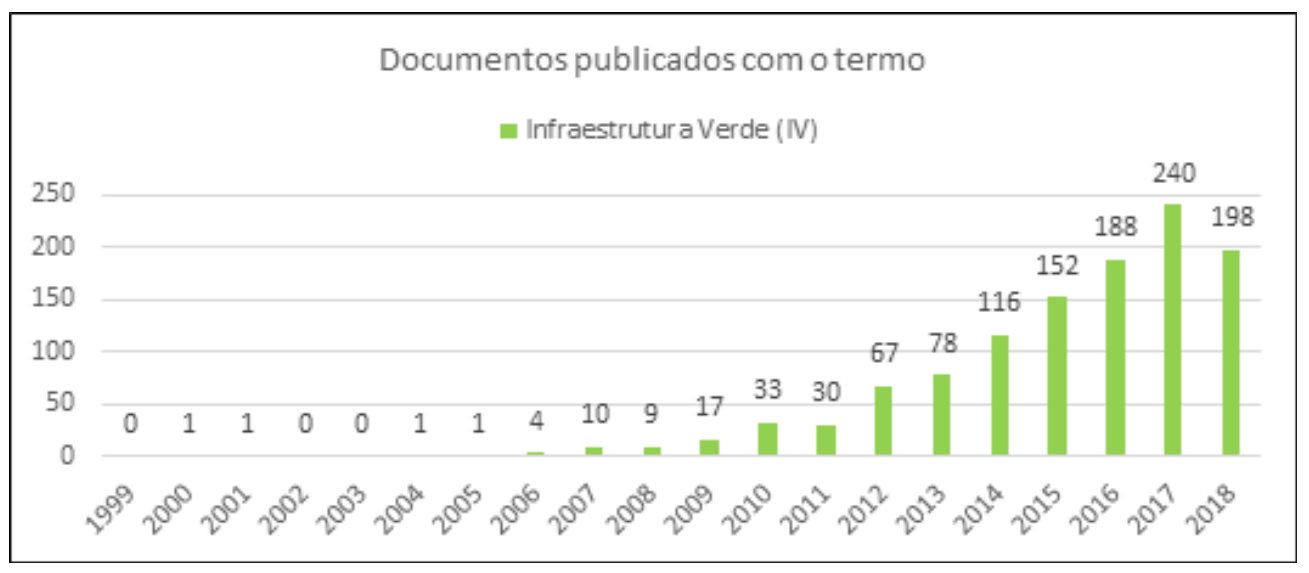

Figura 4: Gráfico mostrando o total de documentos com o termo 'IV' por ano, período entre 1999-2018.

Fonte: Produzido por Santos (2020) sobre dados coletados do Google Acadêmico, 2019.

A Figura 5 expõe um gráfico com os resultados do levantamento que correlaciona a evolução do uso do termo IV com o crescimento das publicações sobre Paisagismo. Além de ser possível destacar o aumento geral do uso do termo 'paisagismo', verifica-se um incremento mais acentuado no número de publicações a respeito da IV. Enquanto da primeira (1999-2008) para a segunda década (2009-2018), o número total de publicações com o termo 'paisagismo' cresce 4 vezes, o número de documentos que contêm simultaneamente os termos 'paisagismo' e 'IV' aumenta 36 vezes. Até 2005, não existia nenhum trabalho que vinculava Paisagismo e IV. No período entre 2006-2011, 1\% dos trabalhos abordavam simultaneamente esses temas. Esse percentual aumenta para $2 \%$ no período entre 2012-2014, para 3\% entre 2015-2017 e, no ano de 2018 , cerca de $4 \%$ das publicações sobre Paisagismo também incluíam menções à IV.

A Figura 6 mostra um gráfico do total de documentos com o termo IV em comparação com os documentos com o termo GI, apresentado em escala logarítmica devido às diferenças entre as curvas. O aumento do interesse no tema observado nas publicações em português também foi constatado nas publicações internacionais. Apesar de o número total de publicações em português ser inferior às publicações em inglês, seu crescimento ocorreu de forma mais marcante.

Na primeira década analisada (1999-2008), o número total de publicações contendo o termo IV (27 documentos) corresponde a apenas $1 \%$ das publicações com o termo GI (2522 documentos).
Porém, na segunda década (2009-2018), o número total de publicações com o termo IV (1119) equivale a 3\% das publicações com o termo GI (33800). Da primeira para a segunda década, o número de publicações com o termo Gl cresceu 13 vezes; com o termo IV, esse crescimento foi de 41 vezes.

\subsection{Detalhamento das categorias nas PUBLICAÇÕES EM IV}

Para refinar os resultados, procedeu-se à avaliação dos documentos para identificar as contribuições de cada categoria. Assim, a Figura 7 apresenta um gráfico comparativo da evolução no número de documentos publicados para cada uma das categorias válidas para este estudo.

Observa-se que a maior parte da produção nacional corresponde às monografias, dissertações e teses (categoria $B$ ), seguida dos artigos em periódicos (categoria A) e artigos em anais de eventos (categoria C). Os livros e manuais (categoria D) disponíveis on-line representam a menor parcela. Com relação ao detalhamento dos documentos da categoria B, a Figura 8 apresenta uma análise das publicações dessa categoria por universidade e tipo de documento. Do total de documentos que continham o termo IV, 184 são dissertações de mestrado, 81 são monografias de conclusão de curso de graduação ou especialização lato sensu e 60 são teses de doutorado. Desses documentos, as principais contribuições são da Universidade de São Paulo (USP), Universidade Federal do Rio de 

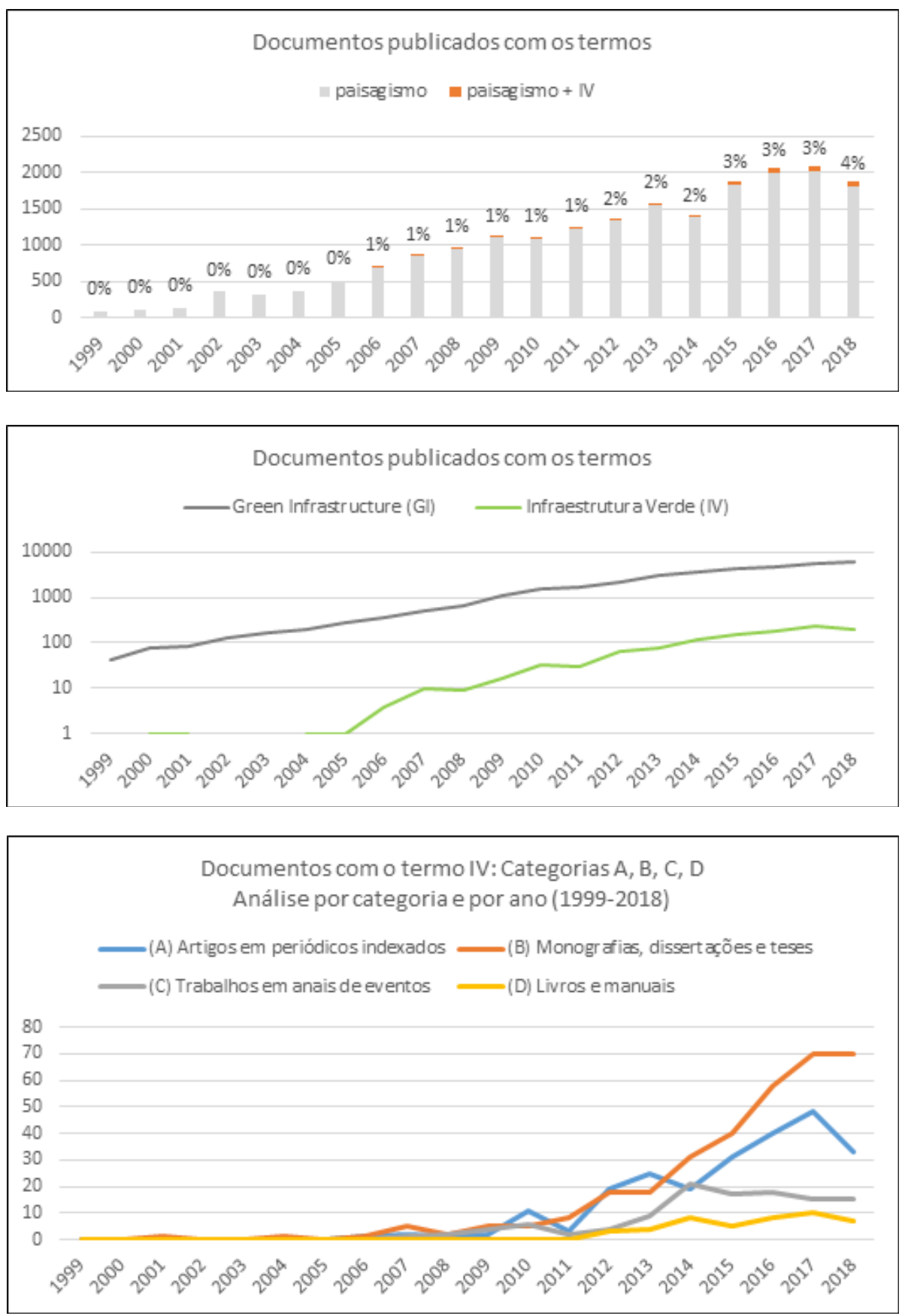

Figura 7: Gráfico comparativo entre os documentos com o termo 'IV' por categoria e por ano, período 1999-2018.

Fonte: Produzido por Santos (2020) sobre dados coletados do Google Acadêmico, 2019.
Figura 5: Gráfico com o total de documentos com o termo 'paisagismo' e 'IV' por ano, período entre 1999-2018. coletados do Google Acadêmico, 2019.

Figura 6: Gráfico comparativo entre os documentos com os termos 'Gl' ou 'IV' por ano, período entre 1999-2018.

Fonte: Produzido por Santos (2020) sobre dados coletados do Google Acadêmico, 2019. 

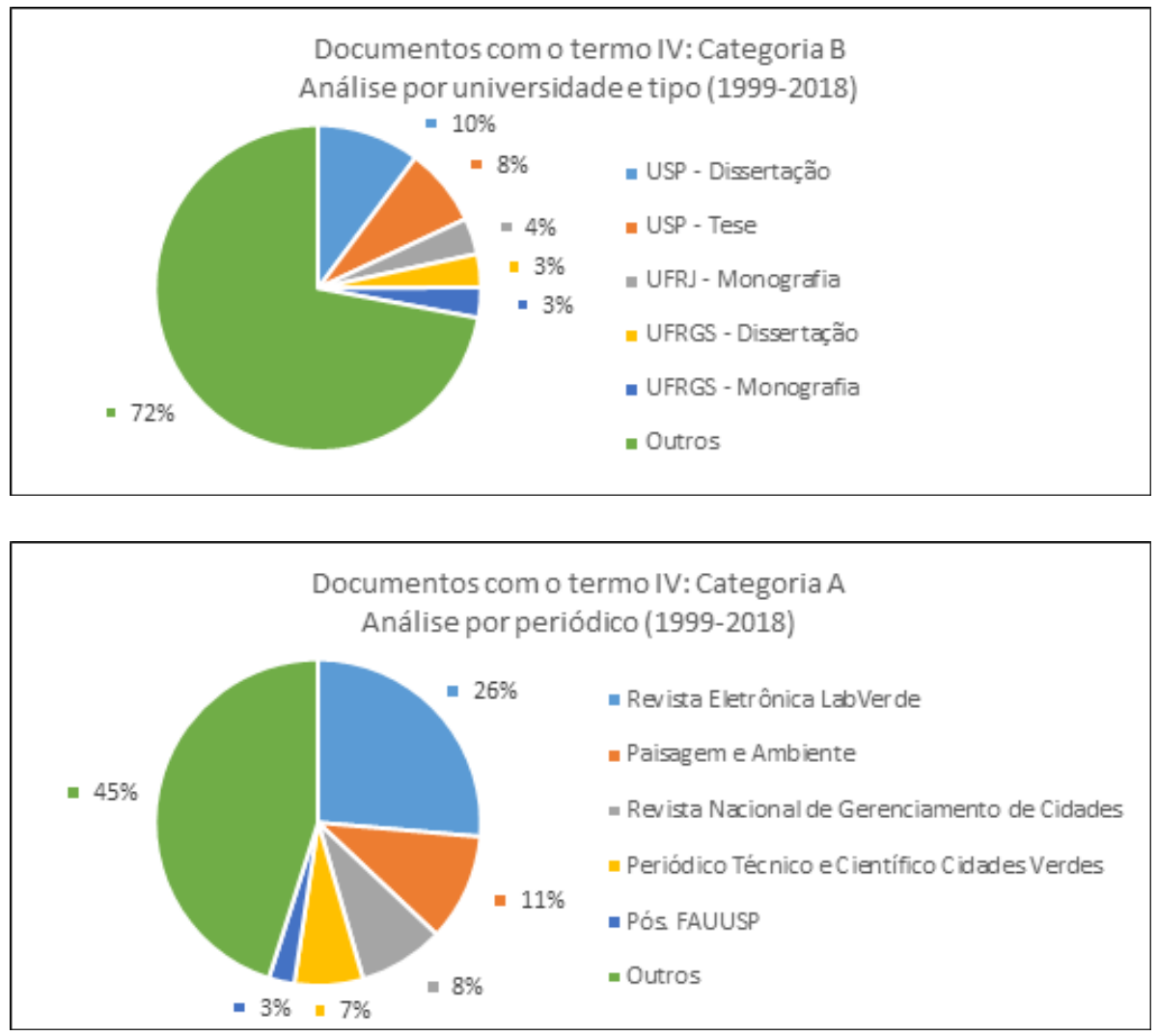

Figura 8: Gráfico mostrando a porcentagem de documentos com o termo 'IV' por universidade e tipo, entre 1999-2018.

Fonte: Produzido por Santos (2020) sobre dados coletados do Google Acadêmico, 2019.

Figura 9: Gráfico mostrando a porcentagem de documentos com o termo 'IV' por periódico, período 1999-2018.

Fonte: Produzido por Santos (2020) sobre dados coletados do Google Acadêmico, 2019.
Janeiro (UFRJ) e Universidade Federal do Rio Grande do Sul (UFRGS). As contribuições das outras universidades públicas ou particulares brasileiras representam os outros dois terços.

Outra análise que poderá orientar futuras pesquisas refere-se aos periódicos que mais publicam artigos com o termo IV. Nesse sentido, a Figura 9 mostra um gráfico com o percentual de publicações por periódico, com destaque para as cinco maiores contribuições para o período.

Observa-se a predominância de periódicos vinculados à USP, com 40\% das contribuições: Revista Eletrônica LabVerde (REL), Paisagem e Ambiente (PA) e Pós. Revista do Programa de PósGraduação em Arquitetura e Urbanismo da FAUUSP (POS). A Revista Nacional de Gerenciamento de Cidades (RNGC) e o Periódico Téc- nico e Científico Cidades Verdes (PTCCD) também são destaques. Interessante observar o quanto a IV, enquanto frente de pesquisa, é recente - dentre os quatro periódicos que mais publicaram sobre o tema (acima de $50 \%$ do total), dois deles iniciaram suas atividades em 2013 (RNGC e PTCCD) e um em 2010 (REL) - o que corrobora a ideia de uma área em expansão.

\subsection{Conceitos, tipologias e terminologia usada NOS ARTIGOS EM IV}

A compilação dos 75 artigos que apresentaram um conceito de IV originaram uma ampla base de dados, que ilustra o estado da arte das publicações sobre o tema no Brasil, e cujas informações subsidiaram as análises apresentadas a seguir. Essa base de da- 


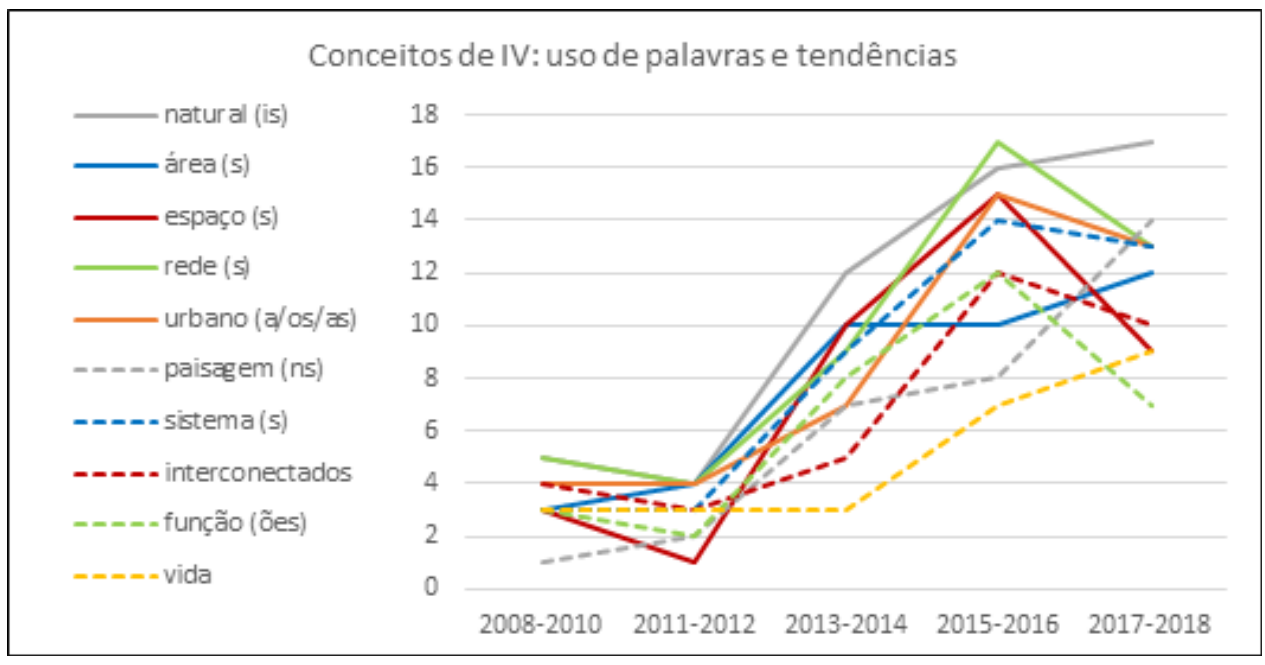

Figura 10: Gráfico mostrando o uso das palavras para definir a IV (2008-2018)

Fonte: Santos e Enokibara (2020)

dos, disponibilizada como material suplementar ${ }^{3}$, pode ser acessada, utilizada e referenciada como Santos e Enokibara (2021), o que certamente poderá auxiliar os futuros trabalhos da área na identificação do referencial bibliográfico. A partir da análise desses artigos, apresenta-se no Quadro 1 uma listagem geral das palavras mais utilizadas pelos autores para definir a IV e, na Figura 10, um gráfico com a evolução e tendências no uso das 10 palavras principais. Além disso, foram contabilizadas 40 referências bibliográficas empregadas pelos autores para definir a IV.

De modo geral, a partir do material compilado foi possível constatar que o core do conceito de IV no Brasil foi cunhado entre os anos 2008-2010: primeiro em 2008, no artigo de Cormier e Pellegrino (2008) em referência a Benedict e McMahon (2006), com o uso das palavras 'espaços', 'naturais' e 'interconectados'; e depois em 2010, nos artigos de Franco (2010), Herzog e Rosa (2010) e Ferreira e Machado (2010), com referência a Benedict e McMahon (2006) e Ahern (2007), por meio das palavras 'rede', 'áreas' e 'urbano'. Como ecos, essas palavras continuaram reverberando em inúmeros artigos posteriores: estima-se que essas 6 palavras estão presentes em mais da metade dos conceitos de IV apresentados nos artigos nacionais. Destaca-se, na Figura 10, uma tendência atual em incluir as palavras 'paisagem' e 'vida', além das habituais 'áreas' e 'naturais' na conceituação da IV, um indicativo do quanto a relação dos usuários com esses espaços está em voga na área.

Quadro 1: Palavras mais utilizadas pelos autores para definir o conceito de IV.

\begin{tabular}{|c|c|c|c|c|c|c|c|}
\hline Posição & Palavras & $\mathrm{N}^{\circ *}$ & $\% * *$ & Posição & Palavras & $\mathrm{N}^{\circ *}$ & $\% * *$ \\
\hline $1^{\circ}$ & Natural (is) & 76 & 69 & $9^{\circ}$ & Função (ões) & 35 & 41 \\
\hline $2^{\circ}$ & Área (s) & 64 & 51 & $10^{\circ}$ & Vida & 31 & 33 \\
\hline $3^{\circ}$ & Espaço (s) & 59 & 49 & $11^{\circ}$ & Ecossistema (s) & 29 & 35 \\
\hline $4^{\circ}$ & Rede (s) & 55 & 64 & $11^{\circ}$ & Águas & 29 & 25 \\
\hline $5^{\circ}$ & Verde (s) & 51 & 39 & $12^{\circ}$ & Cidade (s) & 26 & 31 \\
\hline $6^{\circ}$ & $\begin{array}{l}\text { Urbano (a/ } \\
\text { os/as) }\end{array}$ & 50 & 56 & $12^{\circ}$ & Qualidade (s) & 26 & 29 \\
\hline $7^{\circ}$ & $\begin{array}{l}\text { Paisagem } \\
\text { (ns) }\end{array}$ & 42 & 44 & $13^{\circ}$ & Benefícios & 25 & 28 \\
\hline $8^{\circ}$ & Sistema (s) & 41 & 56 & $14^{\circ}$ & Valores & 24 & 25 \\
\hline $9^{\circ}$ & $\begin{array}{l}\text { Interconec- } \\
\text { tados }\end{array}$ & 35 & 45 & $15^{\circ}$ & $\begin{array}{l}\text { Multifuncional } \\
\text { (is) }\end{array}$ & 23 & 31 \\
\hline
\end{tabular}

Nota: (*) Número total de vezes que essas palavras aparecem no conjunto de definições avaliadas. (**) Percentual dos artigos que utilizam essas palavras na sua definição de IV, com relação ao total (75 documentos). Fonte: Santos e Enokibara (2020). 
Na sequência, o Quadro 2 apresenta uma classificação dos termos mais utilizados para se referir às tipologias de IV e, na Figura 11, um gráfico com a evolução e tendências no uso dos 10 termos principais. Foram contabilizadas 688 referências às tipologias de IV, com 125 termos catalogados.

Observa-se, na Figura 11, uma tendência dos estudos atuais em focar nas tipologias de manejo integrado das águas pluviais, como 'jardins de chuva', 'biovaletas', 'canteiros pluviais', 'tetos verdes' e

Quadro 2: Termos mais utilizados pelos autores para se referir às tipologias de IV.

\begin{tabular}{|c|c|c|c|c|c|c|c|}
\hline Posição & Termos & $\mathrm{N}^{\circ *}$ & $\%$ ** & Posição & Termos & $\mathrm{N}^{\circ *}$ & $\%$ ** \\
\hline $1^{\circ}$ & $\begin{array}{l}\text { Corredores } \\
\text { verdes }\end{array}$ & 46 & 61 & $10^{\circ}$ & $\begin{array}{l}\text { Lagoas } \\
\text { pluviais }\end{array}$ & 15 & 20 \\
\hline $2^{\circ}$ & $\begin{array}{l}\text { Parques } \\
\text { lineares }\end{array}$ & 39 & 52 & $11^{\circ}$ & $\begin{array}{l}\text { Pavimentos } \\
\text { permeáveis }\end{array}$ & 14 & 19 \\
\hline $3^{\circ}$ & $\begin{array}{l}\text { Espaços } \\
\text { abertos }\end{array}$ & 37 & 49 & $12^{\circ}$ & $\begin{array}{l}\text { Fragmentos } \\
\text { permeáveis }\end{array}$ & 13 & 17 \\
\hline $4^{\circ}$ & $\begin{array}{c}\text { Áreas } \\
\text { naturais }\end{array}$ & 31 & 41 & $13^{\circ}$ & $\begin{array}{l}\text { Caminhos } \\
\text { verdes }\end{array}$ & 12 & 16 \\
\hline $4^{\circ}$ & $\begin{array}{l}\text { Jardins de } \\
\text { chuva }\end{array}$ & 31 & 41 & $13^{\circ}$ & $\begin{array}{l}\text { Cinturões } \\
\text { verdes }\end{array}$ & 12 & 16 \\
\hline $5^{\circ}$ & $\begin{array}{c}\text { Arborização } \\
\text { urbana }\end{array}$ & 29 & 39 & $13^{\circ}$ & $\begin{array}{c}\text { Ruas } \\
\text { arborizadas }\end{array}$ & 12 & 16 \\
\hline $6^{\circ}$ & Biovaletas & 28 & 37 & $14^{\circ}$ & $\begin{array}{l}\text { Bacias de } \\
\text { retenção }\end{array}$ & 10 & 13 \\
\hline $7^{\circ}$ & $\begin{array}{l}\text { Corredores } \\
\text { ecológicos }\end{array}$ & 22 & 29 & $14^{\circ}$ & Greenways & 10 & 13 \\
\hline $8^{\circ}$ & $\begin{array}{l}\text { Canteiros } \\
\text { pluviais }\end{array}$ & 19 & 25 & $15^{\circ}$ & Cisternas & 9 & 12 \\
\hline $9^{\circ}$ & $\begin{array}{l}\text { Alagados } \\
\text { construídos }\end{array}$ & 18 & 24 & $15^{\circ}$ & $\begin{array}{l}\text { Redes } \\
\text { verdes }\end{array}$ & 9 & 12 \\
\hline $9^{\circ}$ & Tetos verdes & 18 & 24 & $15^{\circ}$ & Ruas verdes & 9 & 12 \\
\hline
\end{tabular}

Nota: (*) Número total de trabalhos que citam essa tipologia de IV, dentro do conjunto de artigos avaliados. (**) Percentual dos artigos que citam essa tipologia de IV, em relação ao total (75 documentos). Fonte: Santos e Enokibara (2020). 'lagoas pluviais' - além dos bastante difundidos 'parques lineares'. Por outro lado, pesquisas sobre temas mais genéricos apresentaram redução, como 'espaços abertos' ou 'áreas naturais'.

Para avaliar se a área de formação dos autores interfere na definição da IV e na terminologia utilizada para se referir às tipologias, apresenta-se, nos subitens a seguir, uma discussão dos artigos cujo autor principal possui formação distinta das áreas de Arquitetura, Urbanismo e Paisagismo.

\subsection{1. Área: Geografia}

Foram identificados 6 artigos cujos autores principais são Geógrafos (FERREIRA; MACHADO, 2010; BUENO; XIMENES, 2011; SCHUTZER, 2014; BORBA; MENDONÇA, 2015; ALVES, 2017; FARIAS et al., 2018). Para esse grupo, as principais palavras utilizadas para definir a IV são 'rede' (usada por $67 \%$ dos autores), 'naturais' (67\%), 'áreas' (50\%), e 'vida' (67\%). O uso da palavra 'vida' ocorre como referência a uma das principais funções da IV: "uma rede para o suporte da vida" (FERREIRA; MACHADO, 2010 p. 69; BUENO; XIMENES, 2011, p. 130); “contribuindo [...] para a qualidade de vida dos cidadãos" (FERREIRA; MACHADO, 2010, p. 69); ou mesmo que "garantem a qualidade de vida urbana" (BORBA; MENDONÇA, 2015, p. 38). Para definir a IV, dentre as 6 referências utilizadas pelos autores, a mais citada é Benedict e McMahon (2006), usada por 2 autores (33\%).

Verifica-se uma grande heterogeneidade no entendimento do que a IV abrange pelo grupo de Geógrafos, talvez um reflexo das muitas referências utilizadas. $O$ grupo não possui nenhuma tipologia citada por todos os autores, sendo as mais lembradas (por $83 \%$ dos autores): 'corredores verdes' e 'espaços abertos'. Além disso, o grupo faz menção a 37 termos diferentes, com uma média de 12 tipologias por artigo. Para Alves (2017, p. 84), por exemplo, a IV é constituída de 'terrenos abandonados', 'campos encapsulados', 'cemitérios' e 'terrenos da escola'. Enquanto Bueno e Ximenes (2011, p. 132), ao entenderem a IV a partir da ótica da Ecologia da Paisagem, agrupam as tipologias em "manchas, corredores e matrizes". 


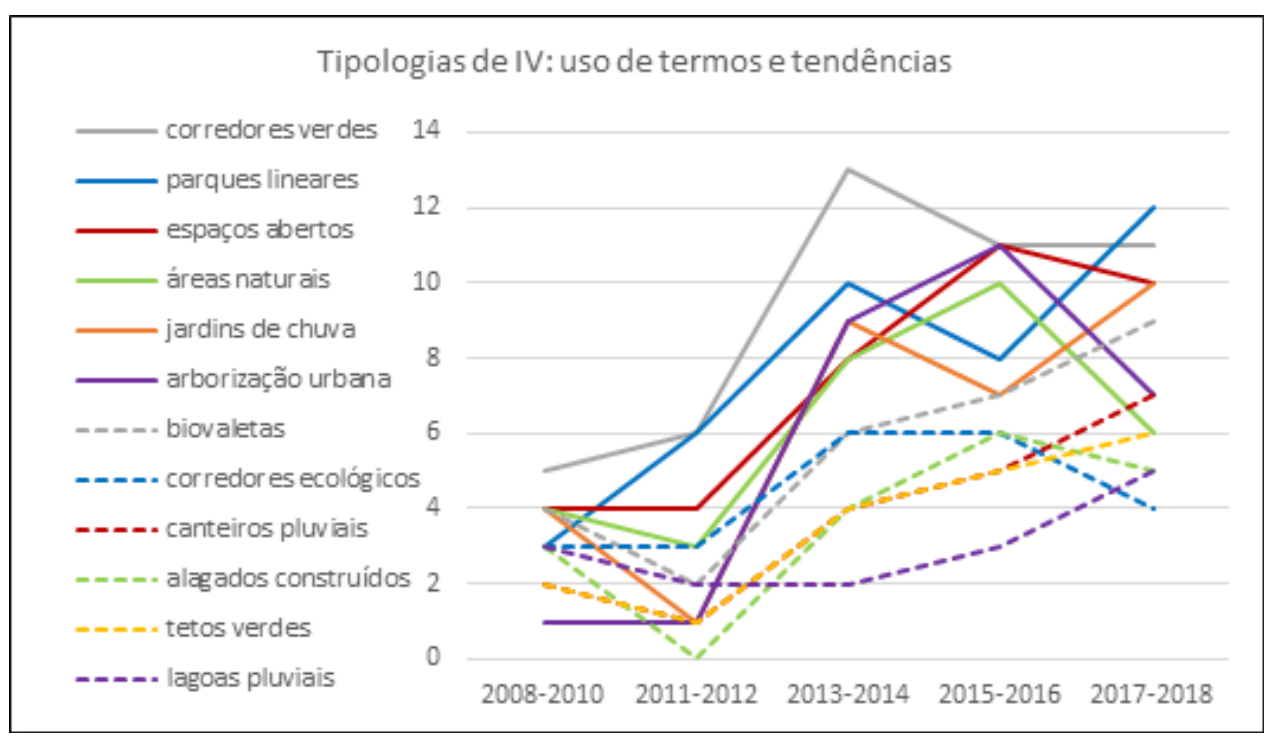

Figura 11: Gráfico mostrando o uso dos termos referentes às tipologias de IV (2008-2018)

Fonte: Santos e Enokibara (2020)

\subsection{2. Área: Direito}

Para os 5 artigos com autores da área do Direito (CARVALHO, 2015; GUIMARÃES, 2015; MARQUES, 2016; SILVA; CARVALHO, 2018; MANTELLI, 2018), além de apresentarem o conceito de IV - empregando para tal as palavras 'áreas' (80\%), 'naturais' $(80 \%)$ e 'espaços' (60\%) - existe uma grande preocupação em definir o que não é a IV, que pode ser entendida sob o viés da objetividade e necessidade de clareza textual do Direito. Assim, os autores também se dedicam a conceituar a 'infraestrutura cinza', a 'infraestrutura construída' ou a 'infraestrutura existente'. O que acarreta na incorporação da palavra 'infraestrutura' (com esse sentido de oposição à IV) entre as palavras mais empregadas pelos autores da área ( $80 \%)$. É interessante observar também o quanto esse grupo é homogêneo, no que se refere à formação: assim como os autores principais, os coautores também são da área do Direito. Para esse grupo, dentre as 4 referências usadas para definir a IV, a mais citada é Benedict e McMahon (2001), usada por 3 autores (60\%).

Em relação ao que a IV abrange, observam-se duas linhas bem definidas dentro do grupo de autores do Direito. Os artigos que abordam Direito dos Desastres (CARVALHO, 2015; MARQUES,
2016; SILVA; CARVALHO, 2018; MANTELLI, 2018), entendem a IV como as áreas naturais que possuem a função de prevenir e atenuar os desastres naturais, citando como 'espécies' dessas áreas (75\%): 'áreas alagadas', 'florestas', 'dunas', 'restingas' e 'marismas'. O trabalho de Guimarães (2015), único que aborda o tema de políticas públicas de IV, entende que a IV abrange uma gama bem maior de práticas, técnicas e tecnologias voltadas à busca da sustentabilidade no meio urbano. Para o autor, a IV inclui desde as já citadas tipologias para manejo de águas pluviais, passando pelo "uso de fontes de energia renováveis" e a "promoção do uso das bicicletas e outras fontes limpas e seguras de transporte". Ao todo, são usados 23 termos pelos autores, média de 6 tipologias por artigo.

\subsection{3. Área: CiênCIAs Biológicas}

Em relação aos 4 artigos com primeiro autor da área de Ciências Biológicas (PINHEIRO, 2015; SANDRE et al., 2015; NUCCI et al., 2016; SETTA, 2017), pode-se comentar que, além do uso das palavras 'urbanas' (100\%), 'naturais' $(75 \%)$ e 'verdes' (50\%), também houve menção à palavra 'ecossistemas' $(50 \%)$. Os autores desse grupo têm uma visão da IV como "ecossistemas urbanos" (NUCCI 
et al., 2016, p. 68) ou "ecossistemas no meio urbano" (PINHEIRO, 2015, p. 137), evidenciando as interrelações, fluxos e ciclos que ocorrem nesses ambientes. Para definir a IV, são citadas fontes distintas pelos autores, que contabilizam 4 referências bibliográficas.

Com 35 termos diferentes e média de 10 tipologias por artigo, o grupo de autores das Ciências Biológicas possui a menor concordância interna de termos entre os autores. Apenas 3 termos são citados por mais de um autor: 'arborização urbana' (75\%), 'alagados construídos' (50\%) e 'wetlands' (50\%). Todos os outros 32 termos são citados por somente um autor dentro do grupo.

\subsection{4. Área: Engenharia Civil}

Os 3 artigos com autores principais Engenheiros Civis (MARQUES et al., 2016; PEREIRA et al., 2018; GUIMARÃES et al., 2018) escolheram a palavra 'naturais' $(100 \%)$ como características dos processos e 'áreas' (67\%) englobadas pela IV. Um ponto interessante, entretanto, se refere às outras palavras empregadas pelo grupo (67\%): 'benefícios', 'valores' e 'funções' são utilizadas pelos autores para justificar o uso da IV e enfatizam os possíveis efeitos positivos que advêm de sua implantação. Para definir a IV, são citadas fontes distintas pelos autores que contabilizam 4 referências.

Com total de 9 termos utilizados e média de 4 tipologias por artigo, os autores da Engenharia Civil apresentam as tipologias mais citadas (67\%): 'corredores verdes' e 'áreas naturais'. Outro ponto a ser frisado é o fato de ter aparecido, apenas nesse grupo, uma referência ao termo Técnicas Compensatórias (TC) para designar o conjunto de tipologias para manejo de águas pluviais, em Pereira et al. (2017). Conforme discutido por Fletcher et al. (2015), em sua ampla revisão da terminologia ao redor do assunto da drenagem urbana mundial, o termo surgiu incialmente na França e foi difundido no Brasil por importantes autores como Baptista et al. (2015). Entretanto, ainda de acordo com Fletcher et al. (2015), à medida que surgiram preocupações como a qualidade paisagística e a integração desses projetos no espaço urbano - e profissionais como os Arquitetos Paisagistas foram inseridos na discussão -, o uso do termo TC se restringiu mais aos campos da hidráulica e hidrologia, enquanto termos como 'integrated urban water management' e 'source control' encontraram aderência mais ampla.

\subsection{5. Área: Engenharia Florestal}

A Engenharia Florestal também se constitui como um grupo bastante homogêneo: são apenas 2 artigos (CARVALHO, 2016; BRUN et al., 2017), mas os 8 autores e coautores são todos da mesma área. Interessante pontuar que a definição de IV desse grupo inclui as árvores não apenas como parte de um maciço vegetal, mas também como um indivíduo - 'indivíduos arbóreos', 'árvores individuais localizadas em áreas urbanas e periurbanas' e até mesmo as 'árvores em locais abandonados', conforme Brun et al. (2017, p. 504) - uma definição possivelmente influenciada pelos conceitos da Silvicultura Urbana. Para definir a IV, cada autor cita fontes distintas, contabilizando 2 referências bibliográficas. A respeito das tipologias dos 5 termos distintos utilizados, apenas a 'arborização urbana' é citada por ambos (100\%).

\subsection{6. Área: Engenharia Ambiental, Gestão e AnÁlise Ambiental}

Assim como na área de Engenharia Florestal, os 2 artigos de autores com formação na área Ambiental (AMATO-LOURENÇO et al., 2016; TÃO et al., 2016) também se destacam pelo uso das palavras 'naturais' e 'arborizados' na hora de definir os espaços incluídos pela IV e pelo interesse na 'arborização urbana'. Somente essa tipologia é citada pelos dois trabalhos (100\%).

Destaca-se, ainda, o artigo de Amato-Lourenço et al. (2016), que pode ser apontado como o único trabalho específico na área de Saúde Pública, com participação de coautores da área Médica e que correlaciona as áreas verdes urbanas e os efeitos positivos associados à saúde humana "[...] em relação a longevidade, doenças cardiovasculares, obesidade, saúde mental, qualidade do 
sono, recuperação de doenças e desfechos de natalidade" (AMATO-LOURENÇO et al., 2016, p. 113).

\subsection{7. Área: Publicidade e Propaganda}

O artigo de Ocke (2017), único com formação em Publicidade e Propaganda, aborda um tópico específico da área, no caso, o Marketing de Lugares. De acordo com Ocke (2017), o tema engloba as técnicas de marketing aplicadas ao fortalecimento da competitividade e da formação da imagem de uma determinada localidade. Apesar de apresentar uma definição bastante completa da IV, o autor não se atém a detalhar as diferentes tipologias de IV e sinaliza apenas que ela é composta de "espaços verdes públicos multifuncionais, bem planejados e de fácil acesso" (OCKE, 2017, p. 148).

\section{Conclusões}

A partir do extenso mapeamento realizado, foi possível identificar algumas tendências. Primeiro, pontua-se o acentuado crescimento do interesse a respeito do tema no Brasil, que contribuiu para disseminar o conceito além das disciplinas em que a IV surgiu. Notadamente, nos últimos 5 anos, o tema foi difundido para outras áreas, e, desde então, autores de pelo menos 5 áreas distintas têm publicado sobre o assunto anualmente. Uma outra questão que pode ser levantada se refere a quanto os autores divergem no entendimento do que a IV pode abranger. Dos 125 termos catalogados para se referir às tipologias, apenas 65 são citados por mais de um dos trabalhos. Esse fato desperta preocupação no que se refere à comunicação entre os autores, haja vista a falta de uma linguagem comum. Em relação a esse ponto, duas fontes podem ter contribuído para a "criação" de novos termos na área: a tradução de material proveniente de outras línguas e sua adaptação ao português, que muitas vezes é realizada de forma literal pelos autores e não considera o que é utilizado em outros textos técnicos no país; e a incorporação de termos como 'eco', 'ecológicos' ou 'verdes'.

Ademais, o uso da bibliometria na revisão da literatura se mostrou eficaz na identificação das bases que compõem o assunto, principalmente na detecção das referências bibliográficas mais citadas e nas relações entre os grupos de autores. Enquanto limitações do estudo, é importante destacar que, em virtude do amplo escopo do trabalho, não foi possível detalhar no texto cada artigo analisado. Em contrapartida, esse extenso levantamento possibilitou a elaboração de uma base de dados - acerca do estado da arte da IV no Brasil, disponibilizada como material suplementar $^{3}$ - que certamente é uma significativa contribuição para futuras pesquisas na área. A transparência, o compartilhamento de informações e a disponibilização de dados primários para acelerar outros trabalhos são iniciativas fundamentais na construção da ciência contemporânea, em qualquer área do conhecimento.

Salienta-se por fim, que, pelo fato de a IV ser um campo de pesquisa recente, ainda existe uma certa discussão entre os autores e uma saudável evolução a respeito do seu entendimento e abrangência: de uma abordagem inicialmente relacionada à conservação ambiental, o conceito de IV está se expandindo para uma estratégia de planejamento em diferentes escalas. Entretanto, tendo em vista sua interdisciplinaridade, é deveras importante a publicação de estudos transversais no tema, para que os autores possam compreender o significado da IV entre seus pares e afinar a linguagem técnica, para alcançar uma audiência mais ampla. Dessa forma, deseja-se promover uma maior integração entre as áreas envolvidas, encontrar os pontos em comum, compreender as divergências e, principalmente, consolidar as bases para o desenvolvimento de novos conhecimentos. 


\section{ReferênCIAS Bibliográficas}

AHERN, Jack. Green infrastructure for cities: the spatial dimension. In: NOVOTNY, V.; BROWN, P. (Orgs.) Cities of the future: Towards integrated sustainable water and landscape management. London: IWA, 2007, p. 267283.

ALVES, Lidiane Aparecida. Ponderações sobre a relevância dos espaços verdes urbanos para as condições de saúde e qualidade de vida. Revista Nacional de Gerenciamento de Cidades, v.5, n.29, p. 7794, 2017. DOI: http://dx.doi.org/10.17271/2 318847252920171522

AMATO-LOURENÇO, Luís Fernando; MOREIRA, Tiana Carla Lopes; ARANTES, Bruna Lara de; SILVA FILHO, Demóstenes Ferreira da; MAUAD, Thais. Metrópoles, cobertura vegetal, áreas verdes e saúde. Estudos Avançados, v. 30, n. 86, p. 113130, 2016. DOI: http://dx.doi.org/10.1590/S010340142016.00100008

BAPTISTA, Márcio; NASCIMENTO, Nilo; BARRAUD, Sylvie. Técnicas Compensatórias em drenagem urbana. 2. ed. Porto Alegre: Editora da ABRH, 2015.

BENEDICT, Mark A.; McMAHON, Edward T. Green infrastructure Linking landscapes and communities. Washington, D.C.: Island Press, 2006.

BENEDICT, Mark A.; MCMAHON, Edward T. Green infrastructure: Smart conservation for the 21st century. Washington, D.C.: Sprawl Watch Clearinghouse, 2001, 32p. Disponível em: http://www.sprawlwatch.org/greeninfrastructure.pdf Acesso em: 22 jan. 2020.

BORBA, Guilherme Galuppo; MENDONÇA, Rebecca. Infraestrutura Verde em Suzano São Paulo. Periódico Técnico e Científico Cidades Verdes, v. 3, n. 5, p. 3555, 2015. DOI: http://dx.doi.org/10.17271/23178604352015953

BRUN, Flávia Gizele Konig; BRUN, Eleandro José; LONGHI, Solon Jonas; GORENSTEIN Maurício Romero; MARIA, Tamara Ribeiro Botelho Carvalho; RÊGO, Géssica Mylena Santana; HIGA, Thatiana Tominaga. Vegetação arbórea em remanescentes florestais urbanos: Bosque do Lago da Paz, Dois Vizinhos, PR. Pesquisa Florestal Brasileira, v. 37, n. 92, p. 503512, 2017. DOI: https://doi.org/10.4336/2017.pfb.37.92.1405 BUENO, Eduardo Silva; XIMENES, Deize Sbrai Sanches. A importância da infraestrutura verde no desenho ambiental: Estudo da área da Cidade Universitária e Instituto Butantã. Revista Eletrônica LabVerde, n. 3, p. 128154, 2011. DOI: https://doi. org/10.11606/issn.21792275.v0i3p12815

CARVALHO, Délton Winter. Os serviços ecossistêmicos como medidas estruturais par prevenção dos desastres. Revista de Informação Legislativa, v. 52, n. 206, p. 5365 2015.

CARVALHO, Natalia Rezende. Princípios de ecologia da paisagem e a prestação de serviços ecossistêmicos para a microbacia do ribeirão do Mandaqui. Revista Eletrônica LabVerde, n. 12, p. 97128, 2016. DOI: https://doi.org/10.11606/issn.21792275. v0i12p97128

CORMIER, Nathaniel S.; PELLEGRINO, Paulo Renato Mesquita. Infraestrutura Verde: uma estratégia paisagística para a água urbana. Paisagem e Ambiente, v. 25, p. 127142, 2008. DOI: https://doi.org/10.11606/issn.23595361.v0i25p127142

FARIAS, Ariadne S.; MARCON, Joceane P.; SCHMITT, Débora P. Infraestrutura urbana sustentável: conceitos e aplicações sob a perspectiva do arquiteto e urbanista. Cadernos de Arquitetura e Urbanismo, v. 25, n. 36, p. 164205, 2018. DOI: https://doi. org/10.5752/P.23161752.2018v25n36p164

FERREIRA, José Carlos; MACHADO João Reis. Infraestruturas Verdes para um futuro urbano sustentável. O contributo da estrutura ecológica e dos corredores verdes.
Revista Eletrônica LabVerde, n. 1, p. 6990, 2010. DOI: https://doi.org/10.11606/ issn.21792275.v0i1p6990

FLETCHER, Tim D. ; SHUSTER, William ; HUNT, Richar Ashley ; BUTLER, David ARTHUR, Scott ; TROWSDALE, Sylvie Barraud; SEMADENIDAVIES, Annette ; BERTRANDKRAJEWSKI, JeanLuc ; MIKKELSEN, Peter Steen ; RIVARD, Gilles; UHL Mathias ; DAGENAIS, Danielle ; VIKLANDER, Maria. SUDS, LID, BMPs, WSUD and more - The evolution and application of terminology surrounding urban drainage. Urban Water Journal, v. 12, n. 7, p. 525-542, 2015. DOI: https://doi. org/10.1080/1573062X.2014.916314

FRANCO, Maria de Assunção Ribeiro. Infraestrutura Verde em São Paulo: O caso do corredor verde IbirapueraVilla Lobos. Revista Eletrônica LabVerde, n. 1, p. 135154 2010. DOI: https://doi.org/10.11606/issn.21792275.v0i1p135154

GIORDANO, Lucilia do Carmo. Análise de um conjunto de procedimentos metodológicos para a delimitação de corredores verdes (greenways) ao longo de cursos fluviais. 2004. 162f. Tese (Doutorado em Geociências) - Instituto de Geociências e Ciências Exatas, Universidade Estadual Paulista, Rio Claro, 2004. GUIMARÃES, Luciana Fernandes; OLIVEIRA, Antonio Krishnamurti Beleño de; VERÍSSIMO, Lays de Freitas; MERLO, Mylenna Linares; VÉROL, Aline Pires. O uso de Infraestruturas Verde e Azul na revitalização urbana e na melhoria do manejo das águas pluviais: o caso da subbacia do rio Comprido. Paisagem e Ambiente, n. 42, p. 7595, 2018. DOI: https://doi.org/10.11606/issn.23595361.v0i42p7595

GUIMARÃES, Renan Eschiletti Machado. Políticas públicas de Infraestrutura Verde urbana: Uma necessidade brasileira e latinoamericana. Revista da Defensoria Pública do Estado do Rio Grande do Sul [online], v. 12, n. 6, p. 251275, 2015.

HERZOG, Cecilia Polacow; ROSA, Lourdes Zunino. Infraestrutura Verde: Sustentabilidade e resiliência para a paisagem urbana. Revista Eletrônica LabVerde n. 1, p. 92115, 2010. DOI: https://doi.org/10.11606/issn.21792275.v0i1p92115

JACSÓ, Peter. Google scholar revisited. Online Information Review, v.32, n.1, p.102 114, 2008. DOI: https://doi.org/10.1108/14684520810866010

KLECHOWICZ, Neuceli Aparecida. Diagnóstico dos acidentes com árvores na cidade de Curitiba PR. 2001. 83f. Dissertação (Mestrado em Ciências Florestais) - Setor de Ciências Agrárias, Universidade Federal do Paraná, Curitiba, 2001.

MANTELLI, Gabriel Antonio Silveira. Dos desastres socioambientais ao direito: fatores aplicáveis e breve quadro jurídico. Revista Direito UFMS, v. 4, n. 1, p. 7495, 2018 DOI: http://dx.doi.org/10.21671/rdufms.v4i1.4871

MARQUES, Sâmia Momesso; VICENTE, Gustavo Zitei; LIMA, César Gustavo da Rocha. Estudo da cobertura vegetal e modelo chuva $x$ vazão na sub bacia do córrego do Luciano Município de Jardinópolis SP. Revista Científica ANAP Brasil, v. 9, n. 7, p. 5973, 2016. DOI: http://dx.doi.org/10.17271/1984324091720161449

MARQUES, Thiago Feltes. O nascimento do Direito dos Desastres no Brasil. Revista Acadêmica Licencia \&acturas, v. 4, n. 1, p. 108123, 2016.

MEHO, Lokman I.; YANG, Kiduk. Impact of data sources on citation counts and rankings of LIS faculty: Web of Science versus Scopus and Google Scholar. Journa of the American Society for Information Science and Technology, v. 58, n. 13, p. 2105-2125, 2007. DOI: https://doi.org/10.1002/asi.20677

NUCCI, João Carlos; BELEM, Anderson Luiz Godinho; KRÖKER, Rudolf. Evolução da paisagem do bairro santa felicidade (CuritibaPR), com base no conceito de 
hemerobia. Revista do Departamento de Geografia USP, v. 31, p. 5871, 2016. DOI: http://dx.doi.org/10.11606/rdg.v31i0.104279

OCKE, Marco Antonio Moraes. O produto ampliado dos lugares: Uma perspectiva de marketing. Revista Interdisciplinar de Marketing, v. 7, n. 2, p. 139155, 2017. DOI: https://doi.org/10.4025/rimar.v7i2.33924

ORDUNA-MALEA, Enrique; AYLLÓN, Juan M.; MARTÍNMARTÍN, Alberto; LÓPEZCÓZAR, Emilio Delgado. Methods for estimating the size of Google Scholar. Scientometrics, v. 104 , p. 931-949, 2015. DOI: https://doi.org/10.1007/s1119201516146

PEREIRA, Priscila Pini; PAREDES, Evaristo Atencio; OKAWA, Cristhiane Michiko.

Diagnóstico preliminar da integridade ambiental de fundos de vale. Engenharia Sanitária e Ambiental, v. 23, n. 4, p. 739749, 2018. DOI: http://dx.doi.org/10.1590/ s141341522018169928

PINHEIRO, Maitê Bueno. Aplicação da fitorremediação em função de tipologias de Infraestrutura Verde em microbacias urbanas da cidade de São Paulo. Revista Eletrônica LabVerde, n. 10, p. 134154, 2015. DOI: https://doi.org/10.11606/ issn.21792275.v1i10p134154

RIBEIRO, Maria Eliana Jubé. Goiânia: Os planos, a cidade e o sistema de áreas verdes. 2000. Universidade de São Paulo, São Carlos, 2000. Dissertação (Mestrado em Arquitetura e Urbanismo) - Universidade de São Paulo, São Carlos, 2000.

SANDRE, Adriana Afonso; MADUREIRA, Flávia Mesquita Sampaio; KUSSUNOKI Marcelo. Trilha urbana, mobilidade e integração social: um estudo aplicado à avenida Sumaré em São Paulo. Revista Eletrônica LabVerde, n. 10, p. 6282, 2015. DOI: https://doi.org/10.11606/issn.21792275.v1i10p6282

SANTOS, Maria Fernanda Nóbrega dos; ENOKIBARA, Marta. Data for: Infraestrutura Verde: conceitos, tipologias e terminologia no Brasil. Mendeley Data, v.1, 2021. DOI: http://dx.doi.org/10.17632/jnvgdhtmd5.1

SCHUELER, Thomas R. Controlling urban runoff: A practical manual for planning and designing urban BMPs. Washington, D.C.: Washington Metropolitan Water Resources Planning Board, 1987

SCHUTZER, José Guilherme. Infraestrutura Verde no contexto da infraestrutura ambiental urbana e da gestão do meio ambiente. Revista Eletrônica LabVerde, n. 8 p. 1330, 2014. DOI: https://doi.org/10.11606/issn.21792275.v0i8p1230

SETTA, Bruno Rocha Silva. Telhados verdes como políticas públicas ambientais para o município de Volta Redonda - RJ. Revista Eletrônica LabVerde, n. 11, p. 1335, 2017. DOI: https://doi.org/10.11606/issn.21792275.v8i1p1335

SILVA, Rodrigo Kempf; CARVALHO, Délton Winter. Aportes iniciais para uma proteção jurídica dos serviços ecossistêmico. Veredas do Direito, v. 15, n. 32, p. 87115, 2018. DOI: http://dx.doi.org/10.18623/rvd.v15i32.1139

TÃO, Nícolas Guerra Rodrigues et al. Proposta metodológica para a análise de áreas verdes: adequações à legislação e à qualidade de vida urbana. Revista Brasileira de Geografia Física, v. 9, n. 6, p. 19101927, 2016. DOI: https://doi.org/10.26848/rbgf. v9.6.p19101927

URBONAS, Ben; STAHRE, Peter. Stormwater detention for drainage, water quality and CSO management. New Jersey: PracticeHall, 1993.

\section{Agradecimentos}

O presente trabalho foi realizado com apoio da Coordenação de Aperfeiçoamento de Pessoal de Nível Superior - Brasil (CAPES)

- Código de Financiamento 001. As autoras agradecem ainda à Profa. Dra. Maria Solange Gurgel de Castro Fontes e à Profa. Dra. Norma Regina Truppel Constantino, pela revisão do material.

\section{Maria Fernanda Nóbrega dos Santos}

Universidade Estadual Paulista "Júlio de Mesquita Filho", Faculdade de Arquitetura, Artes, Comunicação e Design, Programa de Pós-Graduação em Arquitetura e Urbanismo - Campus Bauru Avenida Eng Luiz Edmundo Carrijo Coube, n 14-01, Vargem Limpa, Bauru/SP, CEP 17033360

\section{https://orcid.org/0000000278792349}

mfnsantos@yahoo.com.br

Marta Enokibara

Universidade Estadual Paulista "Júlio de Mesquita Filho", Faculdade de Arquitetura, Artes, Comunicação e Design, Programa de

Pós-Graduação em Arquitetura e Urbanismo - Campus Bauru

Avenida Eng Luiz Edmundo Carrijo Coube, n 14-01, Vargem Limpa,

Bauru/SP, CEP 17033360

https://orcid.org/0000000247907756

marta.enokibara@unesp.br

Nota do Editor:

Submetido em: 15/09/2020

Aprovação: 01/02/2021

Revisão: RMO 